\title{
SUSEPTIBILITAS MAGNETIK DAN KONTAMINASI LOGAM-BERAT DALAM TANAH LAPISAN ATAS DI SEKITAR PABRIK SEMEN DI KOTA PADANG
}

\author{
Afdal, Ulfa Yulius \\ Jurusan Fisika FMIPA Universitas Andalas \\ Kampus Unand, Limau Manis, Padang, 25163 \\ e-mail: afdal@fmipa.unand.ac.id
}

\begin{abstract}
ABSTRAK
Sampel tanah lapisan atas diambil di sepanjang jalan disekitar suatu pabrik semen di kota Padang pada 28 titik yang terbagi atas 3 lintasan. Untuk setiap titik, sampel tanah diambil pada kedalaman $10 \mathrm{~cm}$ sebanyak $100 \mathrm{~g}$. Pengukuran nilai suseptibilitas magnet menggunakan Bartington MS2B Magnetic Susceptibility Meter. Konsentrasi enam jenis logam-berat yaitu $\mathrm{Cu}, \mathrm{Cd}, \mathrm{Pb}, \mathrm{Zn}, \mathrm{Al}$, dan Cr ditentukan dengan Atomic Absorption Spectrometry. Dari penelitian ini diketahui bahwa: nilai rata-rata suseptibilitas magnetik sampel adalah $1.196,5 \times 10^{-5} \mathrm{~m}^{3} \mathrm{~kg}^{-1}$ dengan rentang nilai mulai dari $429,5 \times 10^{-5} \mathrm{~m}^{3} \mathrm{~kg}^{-1}$ sampai $3.560,0 \times 10^{-5} \mathrm{~m}^{3} \mathrm{~kg}^{-1}$; kadar semua jenis logam berat dalam tanah lapisan atas di area penelitian ini relatif tinggi (rata-rata $>35,7 \mathrm{ppm}$ ); kadar logam berat yang ada dalam tanah lapisan atas di area penelitian ini didominasi oleh logam $\mathrm{Al}$; secara umum urutan konsentrasi logam berat dari yang paling besar sampai yang paling kecil hampir sama di seluruh area yaitu $\mathrm{Al}, \mathrm{Zn}, \mathrm{Cu}, \mathrm{Cd}, \mathrm{Cr}, \mathrm{Pb}$; dan tidak teramati pengaruh jarak dari pabrik semen terhadap nilai suseptibilitas maupun konsentrasi setiap jenis logam berat.
\end{abstract}

Kata kunci: logam berat, suseptibilitas magnetik, tanah lapisan atas

\begin{abstract}
Topsoil samples were taken along the road around a cement factory in the city of Padang on 28 points, divided into 3 tracks. For each sampling point, soil samples were taken at a depth of $10 \mathrm{~cm}$, each containing $100 \mathrm{~g}$. Measurement of the magnetic susceptibility values used Bartington MS2B Magnetic Susceptibility Meter. In this study, it was determined the concentration of six heavy metals namely $\mathrm{Cu}, \mathrm{Cd}, \mathrm{Pb}, \mathrm{Zn}, \mathrm{Al}$, and $\mathrm{Cr}$ by Atomic Absorption Spectrometry. The results showed that: the average value of the magnetic susceptibility samples is $1196.5 \times 10^{-5} \mathrm{~m}^{3} \mathrm{~kg}^{-1}$ with a range of values ranging from $429.5 \times 10^{-5} \mathrm{~m}^{3} \mathrm{~kg}^{-1}$ to $3560.0 \times 10^{-5} \mathrm{~m}^{3} \mathrm{~kg}^{-1}$; levels of all types of heavy metals in topsoil in the study area is relatively high (on average greater than $35.7 \mathrm{ppm}$ ); levels of heavy metals in the topsoil in the study area is dominated by the Al metal; generally the order of the concentration of heavy metals from the greatest until the smallest almost the same in all areas, namely $\mathrm{Al}, \mathrm{Zn}, \mathrm{Cu}, \mathrm{Cd}, \mathrm{Cr}, \mathrm{Pb}$, and not observed any effect of distance from the cement plant to susceptibility value and the concentration of each type of heavy metal.
\end{abstract}

Key words: heavy metal, magnetic susceptibility, surface soil 


\section{PENDAHULUAN}

Pencemaran tanah merupakan salah satu masalah lingkungan utama di daerah perkotaan. Salah satu penyebab pencemaran tanah di daerah perkotaan adalah keberadaan polutan berupa emisi gas buang kendaraan bermotor dan pabrik dari aktivitas industri ataupun pertambangan. Jumlah ataupun konsentrasi zat pencemar dapat meningkat seiring dengan bertambahnya aktivitas manusia khususnya di daerah perkotaan seperti aktivitas industri, pertambanagn, dan lalu lintas. Emisi gas buang cenderung membuat kondisi tanah dan air menjadi asam dan menyebabkan terlepasnya ikatan tanah atau sedimen dengan beberapa mineral atau logam, sehingga logam tersebut dapat mencemari lingkungan dan masyarakat sekitar. Kota Padang merupakan salah satu kota besar juga tidak terlepas dari permasalahan pencemaran ini. Partikulat dari emisi pabrik dan kendaraan bermotor yang terbawa angin dapat terdeposisi pada tanah, serta menempel pada daun tumbuhan dan bangunan. Namun dari banyak penelitian, pencemaran akibat emisi pabrik dan kendaraan bermotor sebagian besar terakumulasi pada tanah bagian atas yang bermigrasi ke sistem air atau terakumulasi oleh tumbuhan dan mikroorganisme. Apabila paparan logam berat ada dalam tanah maka masyarakat yang tinggal atau melakukan kegiatan disekitar jalan tersebut akan terpapar oleh bahan pencemar berupa logam yang kadarnya cukup tinggi pula.

Beberapa metode alternatif telah digunakan untuk mengetahui polusi yang terus meningkat. Salah satunya adalah metode magnetik (suseptibilitas) yang telah sukses diterapkan dibeberapa negara Eropa (Kl’učiarová, 2007). Panaiotu dkk. (2005) melakukan penelitian tentang sebaran logam berat di Bucharest degan metode magnetik. Dari penelitian tersebut diketahui bahwa suseptibilitas magnetik dapat digunakan sebagai petunjuk adanya logam berat konsentrasi tinggi pada tanah lapisan atas. Kontaminasi yang dihasilkan oleh aktivitas lalulintas di pusat kota dapat dengan mudah dipetakan dengan suseptibilitas magnetik. Lu dkk., (2005) menyatakan bahwa emisi kendaraan bermotor mengandung partikulat logam berat yang relatif tinggi dan adanya hubungan antara suseptibilitas magnetik dengan logam berat pada tanah. Hal ini menunjukkan bahwa pengukuran dengan menggunakan metode magnetik dapat digunakan sebagai langkah awal untuk mendeteksi pencemaran logam berat.

Untuk mengetahui sebaran logam yang terdapat pada tanah lapisan atas di sekitar pabrik semen di Kota Padang, maka perlu dilakukan penelitian ini. Dengan diketahuinya pola sebaran logam pada tanah lapisan atas maka dapat dijadikan acuan bagi pemerintah kota Padang dalam mengambil langkah-langkah dalam upaya penyelamatan lingkungan. Metode yang digunakan untuk mengidentifikasi logam adalah metode geokimia dan magnetik.

\section{METODOLOGI Waktu Penelitian}

Penelitian ini dilaksanakan dari April sampai Agustus 2012 di Laboratorium Fisika Bumi, Jurusan Fisika, Universitas Andalas.

\section{Peralatan}

Peralatan utama yang digunakan dalam penelitian ini adalah Magnetic Susceptibility Meter (Bartington Magnetic Susceptibility sensor model MS2 dengan dual frequency sensor model MS2B), dan Atomic Absorption Spectrometry (AAS). 


\section{Daerah Penelitian}

Lokasi pengambilan sampel adalah di tiga ruas jalan disekitar pabrik semen sebanyak 28 titik dengan jarak antara titik sampel adalah 500 meter (Gambar 1).

\section{Sampel Tanah}

Sampel diambil pada tanah lapisan atas di sepanjang jalan disekitar suatu pabrik semen di Padang pada 28 titik yang terbagi atas 3 lintasan (Gambar 1). Sampel tanah diambil pada kedalaman $10 \mathrm{~cm}$ sebanyak $100 \mathrm{~g}$. Setiap sampel disimpan dalam kantong plastik, kemudian sampel dikeringkan dan disimpan dalam kantong plastik dan siap untuk dikarakterisasi.

\section{Pengukuran Suseptibilitas Magnetik Tanah}

Untuk menentukan karakteristik magnetik dari sampel tanah dilakukan pengukuran nilai suseptibilitas magnetiknya. Pengukuran suseptibilitas magnetik dilakukan di Laboratorium Fisika Bumi, Jurusan Fisika, Universitas Andalas. Sampel tanah dikeringkan dengan cara meletakkannya di udara terbuka selama satu hari. Setelah kering, dari setiap sampel tanah diambil 6 gr untuk diukur suseptibilitas magnetnya. Pengukuran nilai suseptibilitas magnet menggunakan Bartington MS2B Magnetic Susceptibility Meter. Pengukuran suseptibilitas magnetik untuk setiap sampel dilakukan sebanyak tiga kali.

\section{Pengukuran Geokimia Tanah}

Konsentrasi logam berat ditentukan dengan Atomic Absorption Spectrometry (AAS). Disini akan ditentukan konsentrasi enam jenis logam-berat yaitu $\mathrm{Cu}, \mathrm{Cd}, \mathrm{Pb}, \mathrm{Zn}, \mathrm{Al}$, dan Cr. Pengukuran geokimia ini dilakukan di Laboratorium Air, Jurusan Teknik Lingkungan dan Fakultas Pertanian Universitas Andalas.

\section{HASIL DAN DISKUSI}

Nilai suseptibilitas magnet dari seluruh sampel ditampilkan pada Tabel 1. Dari Tabel 1 dapat dilihat bahwa nilai rata-rata suseptibilitas magnetik sampel adalah $1.196,5 \times 10^{-5}$ $\mathrm{m}^{3} \mathrm{~kg}^{-1}$ dengan rentang nilai mulai dari $429,5 \times 10^{-5} \mathrm{~m}^{3} \mathrm{~kg}^{-1}$ sampai $3.560,0 \times 10^{-5} \mathrm{~m}^{3} \mathrm{~kg}^{-1}$. Nilai konsentrasi setiap logam berat pada tanah lapisan atas disekitar pabrik semen juga dapat dilihat pada Tabel 1 dan grafiknya dapat dilihat pada Gambar 2 sampai 4. Range dan rata-rata konsentrasi setiap jenis logam hampir sama saja untuk semua lintasan.

Dari Gambar 2 sampai 4 teramati bahwa logam Al selalu memiliki konsentrasi tertinggi, dan $\mathrm{Cr}$ dan $\mathrm{Pb}$ memiliki konsentrasi terendah untuk semua lintasan. Dari Gambar 2 dan 4 terlihat kemiripan urutan konsentrasi logam dari yang tertinggi ke yang terendah (Al-Zn$\mathrm{Cu}-\mathrm{Cd}-\mathrm{Pb} / \mathrm{Cr}$ ) antara Lintasan 1 dan Lintasan 3, dimana kedua lintasan ini berada di sebelah selatan pabrik semen. Teramati kemiripan pola antara nilai suseptibilitas dengan konsentrasi logam $\mathrm{Al}$ untuk lintasan 1 dan 2, namun tidak dengan logam lainnya. Juga tidak teramati pengaruh jarak dari pabrik semen terhadap nilai suseptibilitas dan konsentrasi setiap logam berat.

Dari Gambar 2 sampai 4 teramati bahwa logam Al selalu memiliki konsentrasi tertinggi, dan $\mathrm{Cr}$ dan $\mathrm{Pb}$ memiliki konsentrasi terendah untuk semua lintasan. Dari Gambar 2 dan 4 terlihat kemiripan urutan konsentrasi logam dari yang tertinggi ke yang terendah (Al-Zn$\mathrm{Cu}-\mathrm{Cd}-\mathrm{Pb} / \mathrm{Cr}$ ) antara Lintasan 1 dan Lintasan 3, dimana kedua lintasan ini berada di sebelah selatan pabrik semen. Teramati kemiripan pola antara nilai suseptibilitas dengan konsentrasi logam Al untuk lintasan 1 dan 2, namun tidak dengan logam lainnya. Juga tidak teramati pengaruh jarak dari pabrik semen terhadap nilai suseptibilitas dan konsentrasi setiap logam berat. 


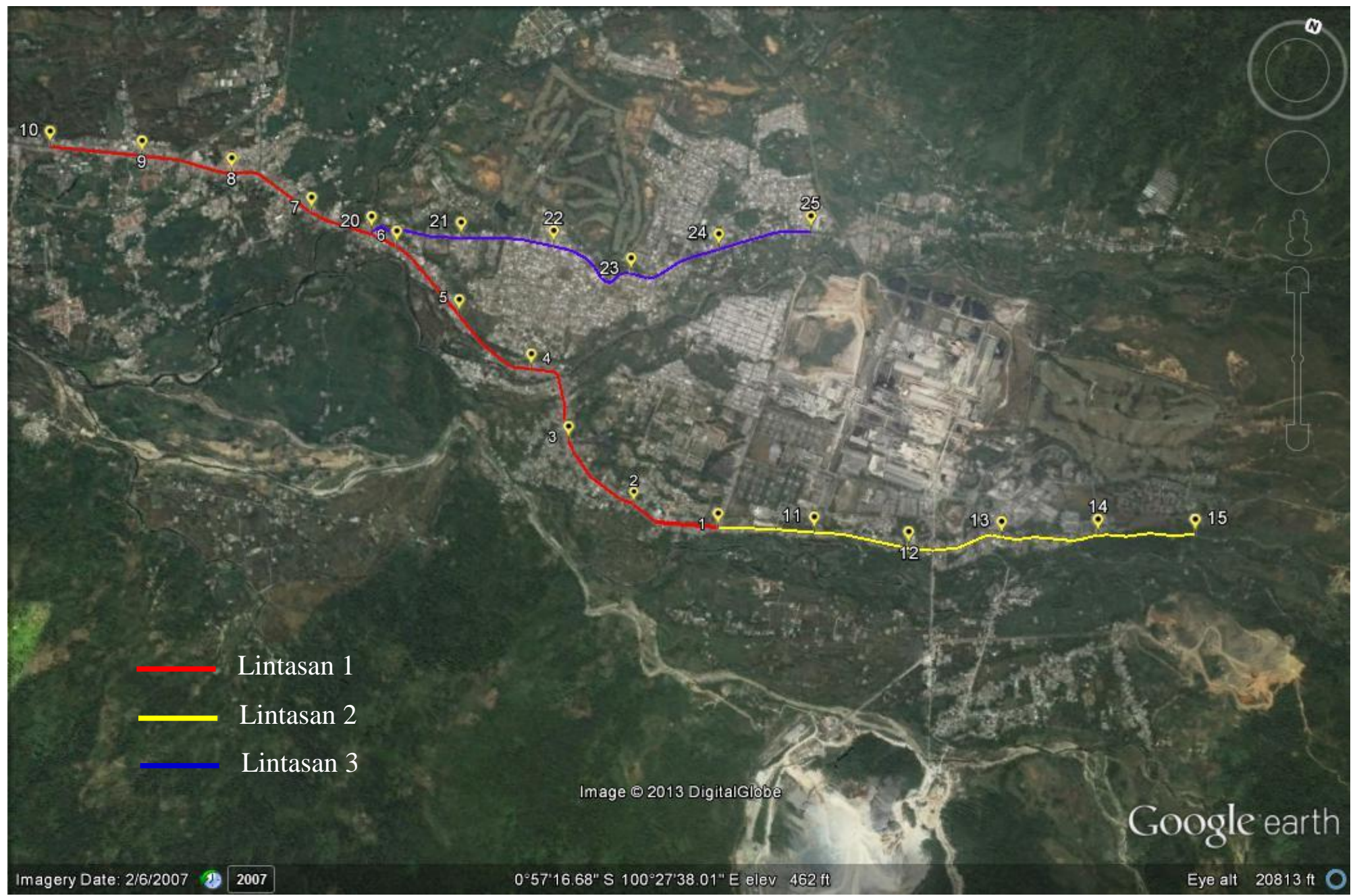

Gambar 1. Lokasi pengambilan sampel tanah disekitar daerah industri di Padang 


\begin{tabular}{|c|c|c|c|c|c|c|c|c|}
\hline \multirow{2}{*}{ No. } & \multirow{2}{*}{$\begin{array}{l}\text { Nama } \\
\text { Sampel }\end{array}$} & \multirow{2}{*}{$\begin{array}{c}\text { Suseptibilitas } \\
\left(10^{-5} \mathrm{~m}^{3} \mathrm{~kg}^{-1}\right)\end{array}$} & \multicolumn{6}{|c|}{ Konsentarasi Logam $(\mathrm{mg} / \mathrm{kg})$ atau $(\mathrm{ppm})$} \\
\hline & & & $\mathrm{Cu}$ & $\mathrm{Cd}$ & $\mathrm{Al}$ & $\mathrm{Cr}$ & $\mathrm{Zn}$ & $\mathrm{Pb}$ \\
\hline 1 & Sampel 1 & 1082,9 & 56,9 & 50,0 & 396,2 & 35,3 & 67,5 & 41,5 \\
\hline 2 & Sampel 2 & 1394,3 & 60,8 & 48,8 & 446,2 & 36,6 & 78,4 & 44,4 \\
\hline 3 & Sampel 3 & 2143,1 & 67,7 & 54,2 & 523,1 & 32,0 & 81,7 & 40,1 \\
\hline 4 & Sampel 4 & 1414,5 & 65,4 & 47,0 & 480,8 & 41,2 & 92,5 & 36,8 \\
\hline 5 & Sampel 5 & 850,9 & 69,3 & 46,4 & 430,8 & 39,5 & 70,0 & 48,1 \\
\hline 6 & Sampel 6 & 3560,0 & 77,7 & 48,8 & 326,9 & 36,2 & 54,2 & 50,5 \\
\hline 7 & Sampel 7 & 429,5 & 83,1 & 37,4 & 453,9 & 32,8 & 91,7 & 31,2 \\
\hline 8 & Sampel 8 & 589,8 & 70,8 & 54,2 & 473,1 & 43,3 & 85,9 & 34,9 \\
\hline 9 & Sampel 9 & 1465,5 & 88,5 & 50,0 & 480,8 & 42,9 & 75,0 & 38,7 \\
\hline 10 & Sampel 10 & 1136,1 & 90,8 & 51,8 & 453,9 & 37,4 & 93,4 & 36,3 \\
\hline 11 & Sampel 11 & 2019,2 & 60,0 & 54,2 & 496,2 & 32,8 & 90,0 & 33,0 \\
\hline 12 & Sampel 12 & 2217,7 & 96,9 & 47,0 & 561,6 & 36,2 & 107,5 & 26,4 \\
\hline 13 & Sampel 13 & 636,2 & 75,4 & 44,6 & 546,2 & 40,4 & 100,9 & 29,3 \\
\hline 14 & Sampel 14 & 444,0 & 63,1 & 49,4 & 353,9 & 44,6 & 66,7 & 34,9 \\
\hline 15 & Sampel 15 & 651,8 & 73,1 & 54,2 & 403,9 & 39,1 & 92,5 & 40,6 \\
\hline 16 & Sampel 16 & 1386,6 & 86,2 & 47,0 & 469,3 & 41,6 & 90,9 & 32,6 \\
\hline 17 & Sampel 17 & 1115,1 & 62,3 & 59,1 & 403,9 & 32,0 & 67,5 & 27,4 \\
\hline 18 & Sampel 18 & 978,1 & 52,3 & 51,8 & 453,9 & 40,4 & 95,0 & 35,4 \\
\hline 19 & Sampel 19 & 690,5 & 73,1 & 57,3 & 403,9 & 43,3 & 73,4 & 38,7 \\
\hline 20 & Sampel 20 & 660,2 & 76,9 & 47,0 & 480,8 & 37,8 & 86,7 & 34,0 \\
\hline 21 & Sampel 21 & 1191,6 & 66,2 & 61,5 & 457,7 & 32,8 & 92,5 & 26,4 \\
\hline 22 & Sampel 22 & 1150,4 & 60,0 & 50,0 & 430,8 & 35,3 & 79,2 & 30,7 \\
\hline 23 & Sampel 23 & 950,4 & 53,9 & 54,2 & 503,9 & 37,8 & 86,7 & 44,4 \\
\hline 24 & Sampel 24 & 785,2 & 88,5 & 53,0 & 461,6 & 41,6 & 90,0 & 38,7 \\
\hline 25 & Sampel 25 & 879,7 & 93,1 & 47,6 & 388,5 & 39,1 & 80,9 & 36,8 \\
\hline 26 & Sampel 26 & 668,3 & 75,4 & 57,3 & 430,8 & 43,3 & 75,9 & 29,7 \\
\hline 27 & Sampel 27 & 2382,0 & 62,3 & 51,8 & 473,1 & 44,6 & 92,5 & 28,8 \\
\hline 28 & Sampel 28 & 627,1 & 56,9 & 47,0 & 288,5 & 32,0 & 50,9 & 29,3 \\
\hline & Rata & 1196,5 & 71,6 & 50,8 & 445,5 & 38,3 & 82,5 & 35,7 \\
\hline & Maks & 3560,0 & 96,9 & 61,5 & 561,6 & 44,6 & 107,5 & 50,5 \\
\hline & Min & 429,5 & 52,3 & 37,4 & 288,5 & 32,0 & 50,9 & 26,4 \\
\hline & STDV & 709,9 & 12,7 & 5,0 & 61,1 & 4,1 & 13,4 & 6,4 \\
\hline
\end{tabular}




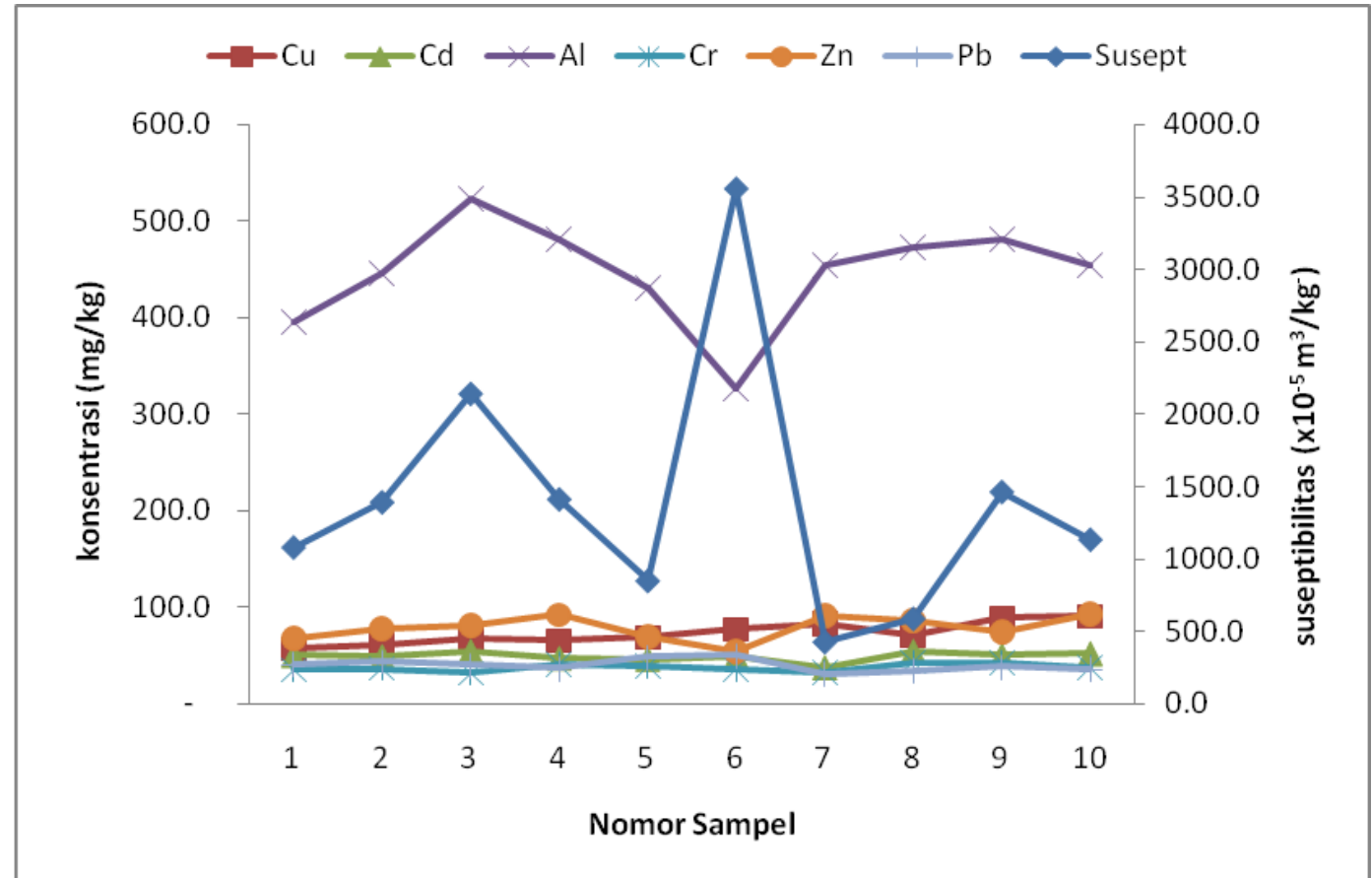

Gambar 2. Grafik konsentrasi logam berat dan suseptibiltas sampel tanah pada Lintasan 1

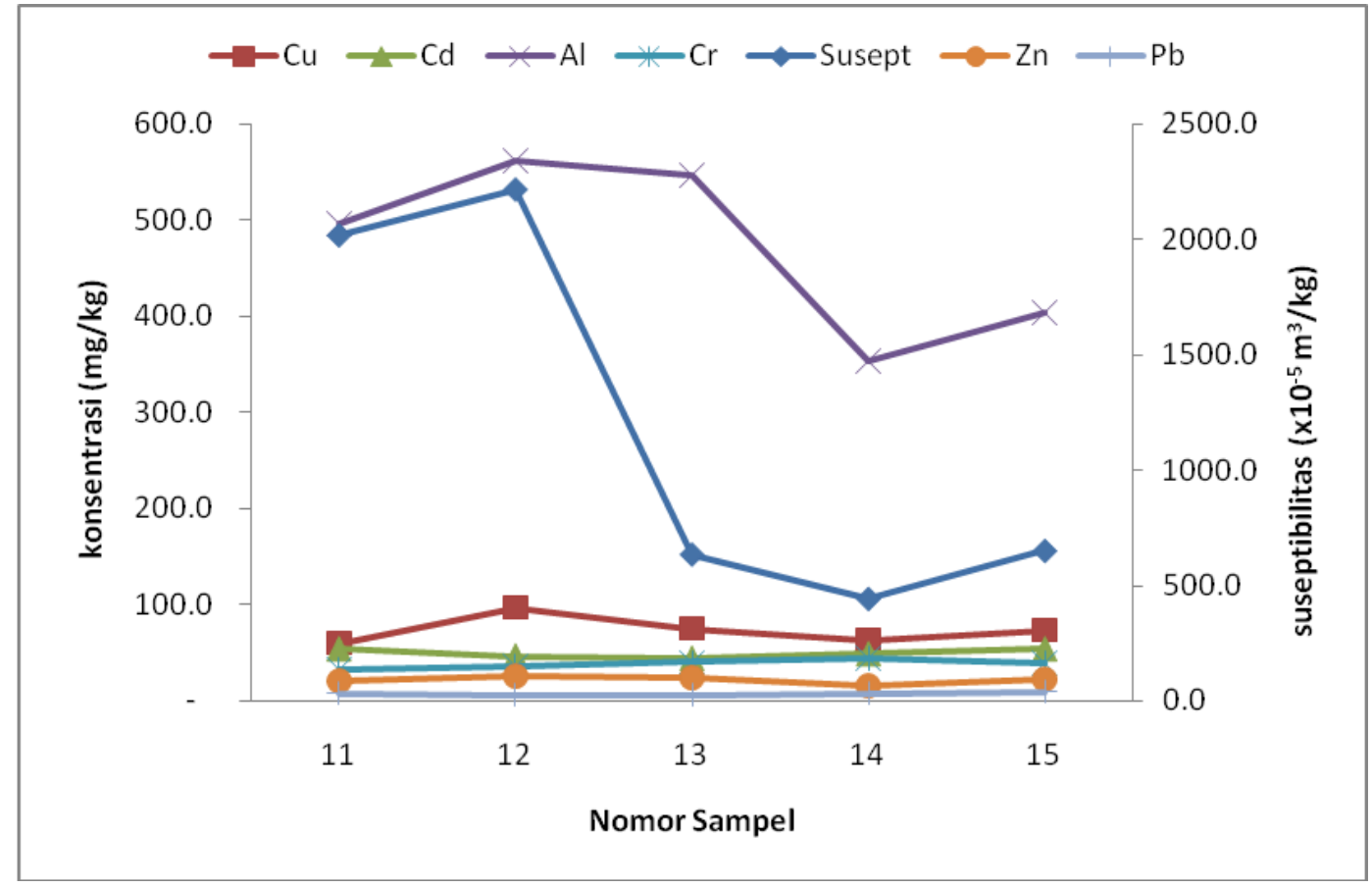

Gambar 3. Grafik konsentrasi logam berat dan suseptibiltas sampel tanah pada Lintasan 2 


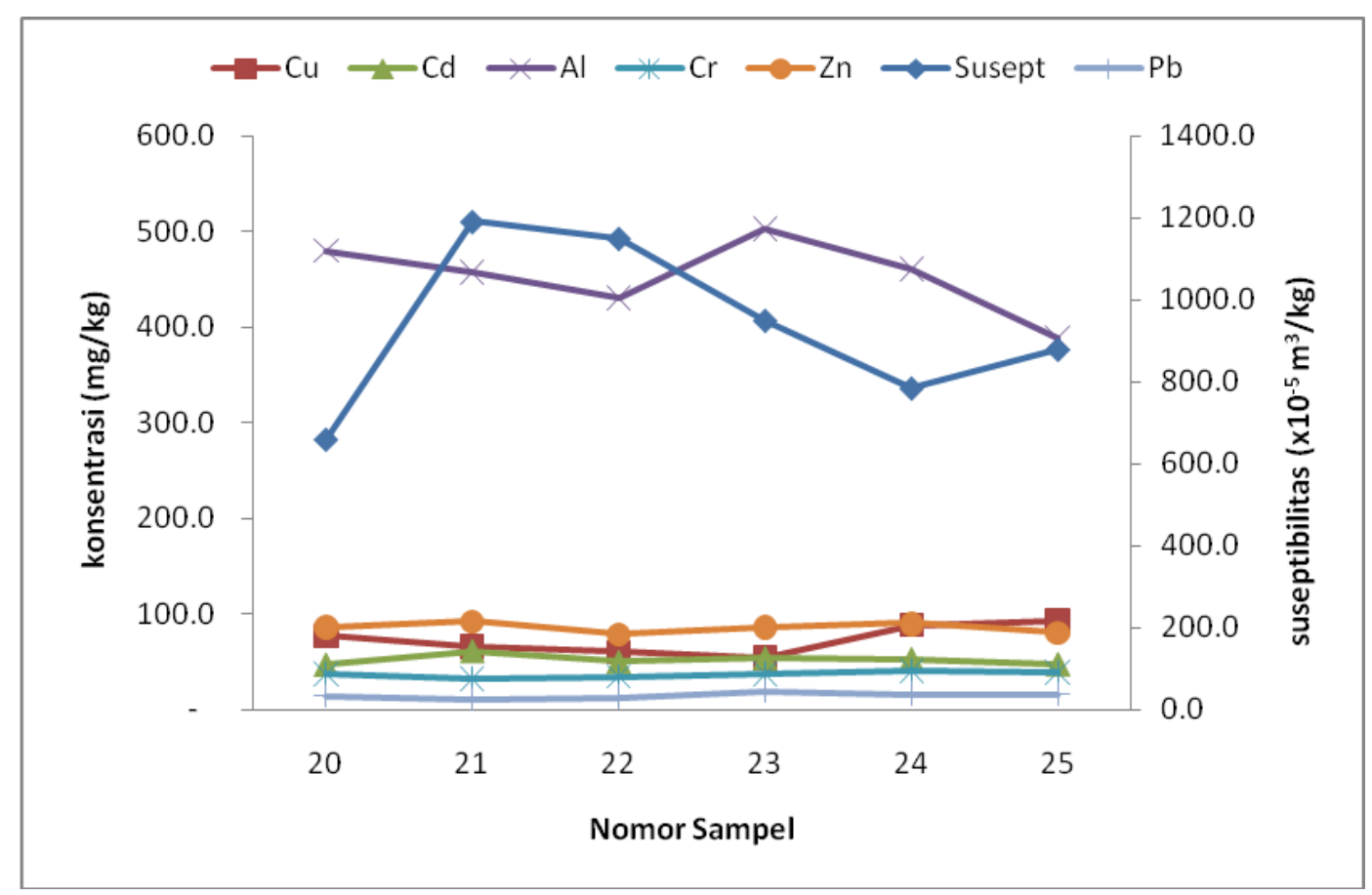

Gambar 4. Grafik konsentrasi logam berat dan suseptibiltas sampel tanah pada Lintasan 3

\section{KESIMPULAN}

1. Kadar semua jenis logam berat dalam tanah lapisan atas di area penelitian ini relatif tinggi.

2. Kadar logam berat yang ada dalam tanah lapisan atas di area penelitian ini didominasi oleh logam Al.

3. Secara umum urutan konsentrasi logam berat dari yang paling besar sampai yang paling kecil hampir sama di seluruh area yaitu $\mathrm{Al}, \mathrm{Zn}, \mathrm{Cu}, \mathrm{Cd}, \mathrm{Cr}, \mathrm{Pb}$.

4. Tidak teramati pengaruh jarak dari pabrik semen terhadap nilai suseptibilitas maupun konsentrasi setiap jenis logam berat.

\section{DAFTAR PUSTAKA}

1. Kl’učiarová, D., D. Gregorová, 2007, Magnetic Susceptibility Mapping of Roadside Pollution, Acta Facultatis Ecologiae, 16: Suppl. 1, 119-123 Zvolen (Slovakia)

1. Panaiotu, C.G., Necula, C., Panaiotu, C.E., Axente, V., 2005, A Magnetic Investigation Of Heavy Metals Pollution In Bucharest, Sustainability for humanity \& environment in the extended connection field science-economypolicy, Scientific reunion of the special program of Alexander von Humbold Foundation concerning the reconstruction of the South Eastern Europe, Editura Politehnica, Timisoara.

2. Hemetsberger, Magnetic Susceptibility Mapping In Austria: A Case Study.

3. Hoffman et al.,( (2007), Magnetic Susceptibility Mapping of roadside Pollution. Geologie and Palantologie, Geophysik, Tubingen. Germany.

4. Lu et al., (2005). Magnetic Properties and Heavy Metalscontens of automobile

5. Emission particulate. Enviromental and Resource Scient, China. 